\title{
Heterogeneous photocatalysis on construction materials: effect of catalyst properties on the efficiency for degrading NOx and self cleaning
}

\author{
N. Bengtsson ${ }^{\mathrm{a}}, \mathrm{M}$. Castellote ${ }^{\mathrm{a}} \bowtie$ \\ a. Institute of Construction Science Eduardo Torroja-IETcc (CSIC) - (Madrid-Spain) \\ $\triangle$ Martaca@ietcc.csic.es
}

Received 29 July 2013

Accepted 12 December 2013

Available on line 19 May 2014

\begin{abstract}
This paper analyzes the effect of some properties of different catalysts on the photocatalytic activity. The efficiency has been determined for two different processes: NOx abatement and self-cleaning for Rhodamine $\mathrm{B}$ and tobacco extract being, the $\mathrm{TiO}_{2}$ based photocatalyst, supported as coatings on white mortar. Eight different catalysts were tested, seven commercial ones and one home-made catalyst with improved visible light absorption properties. Additionally, some of them were submitted to exposition to water and/or calcinations to alter their physical properties. A kinetic approach was used to evaluate the photocatalytic activity, being the first reaction constant (for NO) and just empirical constants (for self-cleaning) the parameters used for the comparison of the different materials. As a result, the efficiency, even for ranking, is dependent on the type of contaminant used in the experiment. In general, NO oxidation and tobacco followed similar trends while no clear relations were found for Rhodamine B.
\end{abstract}

KEYWORDS: $\mathrm{TiO}_{2}$; Optical; Crystalline and microstructure properties; NOx removal; Self cleaning; Rhodamine B; Tobacco extract; Construction materials

Citation / Citar como: Bengtsson, N.; Castellote, M. (2014) Heterogeneous photocatalysis on construction materials: effect of catalyst properties on the efficiency for degrading NOx and self cleaning Mater. Construcc. 64 [314], e013 http://dx.doi.org/10.3989/mc.2014.06713.

RESUMEN: Fotocatálisis heterogénea en materiales de construcción: efecto de las propiedades de los catalizadores en la eficiencia de degradación de NOx y autolimpieza. En este trabajo se analiza el efecto de las propiedades de distintos catalizadores en la actividad fotocatalítica de degradación de NOx y autolimpieza, para Rodamina B y extracto de tabaco. Se han ensayado ocho fotocatalizadores, basados en $\mathrm{TiO}_{2}$ y soportados sobre mortero blanco; siete de ellos comerciales y uno sintetizado en el laboratorio con absorción mejorada en el visible. Adicionalmente, las propiedades físicas de algunos de ellos se alteraron mediante tratamientos con agua y/o por calcinación. La actividad fotocatalítica se ha evaluado mediante aproximación cinética, siendo la constante de reacción de primer orden (para NO) y constantes empíricas de ajuste (para autolimpieza) los parámetros de comparación entre materiales. Como resultado, la eficiencia depende del contaminante utilizado en el experimento de evaluación. En general, en este estudio, oxidación de NO y de extracto de tabaco presentan tendencias similares mientras para Rodamina B no se encontró correlación clara ninguna.

PALABRAS CLAVE: $\mathrm{TiO}_{2}$; Propiedades ópticas, cristalográficas y microestructurales; Degradación de NOx; autolimpieza; Rodamina B; Extracto de tabaco; Materiales de construcción

Copyright: (C) 2014 CSIC. This is an open-access article distributed under the terms of the Creative Commons Attribution-Non Commercial (by-nc) Spain 3.0 License. 


\section{INTRODUCTION}

Photocatalysis is classified as an advanced oxidation process. It is equivocal when and who started utilizing first such a photochemical power of $\mathrm{TiO}_{2}$ to induce chemical reactions. However, it was in the early 1970 s when this discipline becomes more popular with Fujishima and Honda (1) and Wrighton et al. (2) that reported the photocatalytic splitting of water on $\mathrm{TiO}_{2}$ and $\mathrm{Sr}$-doped $\mathrm{TiO}_{2}$ respectively. The application of photocatalytic materials has increased rapidly in construction materials, trying to profit of the extensive surfaces that they can provide, for environmental protection, self-cleaning, self-sterilizing materials, antifogging mirrors and windows. The photocatalytic activity of $\mathrm{TiO}_{2}$ enriched building materials has been reported to provide promising results for the degradation of air contaminates such as VOC (3-5), NOx (6-9) and for self cleaning $(10,11)$ and the expectations of their possibilities increase every day. As an example, very recently, the possibility of using heterogeneous photocatalysis to diminish the allergenic airborne pollen has been reported (12).

$\mathrm{TiO}_{2}$ based catalysts commonly found in the literature have very different catalysts properties so, sometimes is very difficult to compare the results achieved in different trials. Therefore, is important to consider and understand the influence of the different catalyst properties on the photocatalytic activity. Additionally, as in construction activity $\mathrm{TiO}_{2}$ can be dispersed into other materials, as cement, the influence of the interactions of both and the resulting microstructure is also important $(11,13-15)$.

Concerning the first aspect, several papers can be found in literature, mainly on the influence of the crystal size on the optical properties and on the efficiency of the photocatyst.

It is known that the band gap of a crystalline semiconductor is a function of the particle size (16-18). Below a certain threshold, decrease in particle size brings about reduction in band gap, that is, red-shift in absorption spectrum. When the size of semiconductor particle decreases from its bulk to that of Bohr radius, e.g., the first excitation state, the size quantization (quantum size effect, QSE) effect arises due to the spatial confinement of charge carriers. Therefore, the band gap of ultra-fine semiconductor particle increases with the decrease in particle size when it is smaller than the band gap minimum. Size quantization effect has been studied using various semiconductors including $\mathrm{TiO}_{2}(19-21)$. The reported QSE of semiconductor clusters appears to be between 1 and $12 \mathrm{~nm}$. Results of these studies were mostly obtained theoretically, and only a few investigations have been conducted on the change of band gap as a function of particle size using $\mathrm{TiO}_{2}$ (19-22). Anpo et al. (19) studied the change of band gap of $\mathrm{TiO}_{2}$ over a wide range of particle sizes (e.g., 3.8-200 nm) and found significant blue shifts of the absorption edge by 0.093 and $0.156 \mathrm{eV}$ for rutile and anatase crystalline, respectively, when particle size was less than $12 \mathrm{~nm}$. Kormann et al. (20) observed the quantum confinement effect upon illumination of $\mathrm{TiO}_{2}$ colloids and reported a blue-shift by $0.15-0.17 \mathrm{eV}$ in absorption spectrum. However, Serpone et al. (22) did not observe a quantum size effect in the particles size range between 2.1 and $26.7 \mathrm{~nm}$ of $\mathrm{TiO}_{2}$. On the other hand, particle size can also affect the photocatalytic reactivity. A few studies have been conducted to assess the relationship between particle size and photocatalytic reactivity $(19,23-32)$. As recent examples, in (33) the influence of optical properties on the size of two anatase $\mathrm{TiO}_{2}$ nanocrystallines was studied. (34) investigated photocatalytic performances in relation to photocatalyst properties and influence of the chemical environment of cement on titania particles for two commercial anatase samples in cement and mortar specimens: a micro-sized, $\mathrm{m}-\mathrm{TiO}_{2}$ and a nanosized, $\mathrm{n}-\mathrm{TiO}_{2}$. In (35) it was found that crystallinity, rather than surface area or porosity, was the crucial parameter that favours the photocatalytic oxidation of TCE over anatase.

However, most these studies were performed on UV-vis absorbance measurements conducted on suspensions, and considering in isolated way the effect of the different parameters. In this context, this work evaluates the influence of catalyst properties on the NOx abatement and self-cleaning activity, on hardened construction materials enriched with $\mathrm{TiO}_{2}$, with the purpose to evaluate the obtained results for different catalyst properties. A wide range of photocatalysts were selected with different material properties, referring to crystal phases, surface area, optical properties and particle size. The photocatalytic activity of each catalyst was determined by NOx oxidation and self-cleaning tests based on the discoloration of Rhodamine B and tobacco.

\section{EXPERIMENTAL}

\subsection{Catalysts}

The photocatalytic materials used in this study were all based on $\mathrm{TiO}_{2}$. Eight different catalysts were tested, where seven were commercial photocatalysts (A, B, C, D, E, F, G) and one was a home-made S, N and $\mathrm{C}$ doped catalyst $\left(\mathrm{S}-\mathrm{TiO}_{2}\right)$ with improved visible light absorption properties (36). They were of two types: fine powders (A, B, C, D, E and $\mathrm{S}-\mathrm{TiO}_{2}$ ) and white paints ( $\mathrm{F}$ and $\mathrm{G}) \mathrm{TiO}_{2}$ enriched. The paint $\mathrm{G}$ was mentioned by the producer to be activated by visible light.

To achieve a wide range of catalysts properties except for the paints and for $\mathrm{S}-\mathrm{TiO}_{2}$, samples of the catalysts were submitted to exposition to water and 
TABLE 1. Pretreatment of the catalysts

\begin{tabular}{|c|c|c|c|}
\hline Catalytic material & No treatment & Exposure to water & Annealing \\
\hline A & $\mathrm{X}$ & $\mathrm{X}$ & $\mathrm{X}$ \\
\hline B & $\mathrm{X}$ & $\mathrm{X}$ & $\mathrm{X}$ \\
\hline $\mathrm{C}$ & $\mathrm{X}$ & $\mathrm{X}$ & $\mathrm{X}$ \\
\hline $\mathrm{D}$ & $\mathrm{X}$ & $\mathrm{X}$ & $\mathrm{X}$ \\
\hline $\mathrm{E}$ & $\mathrm{X}$ & $\mathrm{X}$ & $\mathrm{X}$ \\
\hline $\mathrm{F}$ & $\mathrm{X}$ & - & - \\
\hline G & $\mathrm{X}$ & - & - \\
\hline $\mathrm{S}-\mathrm{TiO}_{2}$ & $\mathrm{X}$ & - & $\mathrm{X}$ \\
\hline
\end{tabular}

calcinations respectively to alter their crystal properties. Provided that when using powdered photocatalysts, at least when dispersed in a cementitious matrix, they are in contact with an aqueous phase, we considered it was important to analyse also the catalysts after they were subjected to water in order to look mainly for aggregates that could eventually change the size of the crystals with respect to that in a dry state. Concerning calcinations, the catalysts were heated until $800^{\circ} \mathrm{C}$ during 6 hours with a prior temperature increasing using a ramp of $1.8^{\circ} \mathrm{C}$ per minute until reaching $800{ }^{\circ} \mathrm{C}$. The catalysts were let to cool down slowly inside the oven after the annealing.

The resulting table of catalyst (before and after pre-treatments) is summarized in table 1.

\subsubsection{Sample preparation}

The different photocatalysts included in this work were tested by applying them on the surface of white mortar.

The mortar was prepared according to the standards UNE-EN 196-1 (UNE-EN 196-1) and UNE-EN 197-1 (UNE-EN 197-1). White cement BL II/A-LL $52.5 \mathrm{~N}$ was used. The water/cement ratio was 0.50 . The quantities for the batches were $450 \pm 2 \mathrm{~g}$ of cement, $1350 \pm 5 \mathrm{~g}$ of sand and $225 \pm 1 \mathrm{~g}$ of water. The mortar was moulded in Petri dishes with a diameter of $90 \mathrm{~mm}$ and a height of $16 \mathrm{~mm}$. The fresh mixture in the mould was vibrated to remove the air from the mixture and finally excessive mortar was removed to obtain a flat surface. The fresh mortar in the Petri dish was cured for 28 days at $>95 \% \mathrm{RH}$ and $23 \pm 2{ }^{\circ} \mathrm{C}$ inside a humidity chamber.

The paints were applied directly on the surface and distributed homogeneously by a metal roller, giving a homogeneous layer of paint with a mass load of around $300 \mathrm{~g} / \mathrm{m}^{2}$. The powder catalysts were applied as a mixture of water $/ \mathrm{TiO}_{2}$, see description of the $\mathrm{TiO}_{2}$ application below.

A circular area of $50.2 \mathrm{~cm}^{2}$ on the surface of the mortar samples was delimited by silicone. A solution made up of a $\mathrm{TiO}_{2}$ at a concentration of $8.37(\mathrm{~g} / \mathrm{l})$ in deionised water, stirred rigorously during $10 \mathrm{~min}-$ utes was applied on the delimited area. A total volume of $3 \mathrm{ml}$ taken directly from the mixture while stirred to avoid the sedimentation of the catalyst was distributed over the saturated sample's surface, to give a final $\mathrm{TiO}_{2}$ mass load of $5 \mathrm{~g} / \mathrm{m}^{2}$ after evaporation of the water at room temperature. This method for coating was chosen in order to not have a significant influence of the substrate. In fact, the samples were water saturated prior to add the $\mathrm{TiO}_{2}$ suspension; so, nothing was sucked inside the samples. However, being a porous support, the adherence was enough good.

The samples were stored at $57 \% \mathrm{RH}$ and $21{ }^{\circ} \mathrm{C}$ at least 48 hours prior to the NO oxidation and self cleaning degradation tests. The humidity and temperature were controlled by storing the samples in a closed plastic container with a saturated water solution of magnesium nitrate $\left(\mathrm{Mg}\left(\mathrm{NO}_{3}\right)_{2} \cdot 6 \mathrm{H}_{2} \mathrm{O}\right)$ in the bottom. The samples were placed on a plastic grid to avoid contact between the samples and the liquid. The container was stored in a room with controlled temperature of $21^{\circ} \mathrm{C}$.

\subsubsection{Characterisation trials}

The catalysts were characterized for their crystallographic phases, porosity and optical properties:

X-Ray Diffraction analysis allowed to known the crystallographic phases, the crystallite size and the degree of crystallinity (FWHM). The crystal size was determined according to the Scherrer's equation, Equation [1]:

$$
d=\frac{\mathrm{K} \lambda}{\beta \cos \theta}
$$

where $d$ is the average particle size of the phase under investigation, $K$ is the Scherrer's constant, $\lambda$ is the $x$-ray wavelength used $(1.5406 \AA), \beta$ is the width at mean height of the diffraction peak expressed in radians and $\theta$ is the angle in radians of the diffraction peak. The value of the Scherrer constant (K) depends on normalized Grain Size Distribution width. 
Surface area measurements were made by BET multipoint method, using $\mathrm{N}_{2}-77 \mathrm{~K}$ gas. The surface area was calculated from the sorption isotherm data in the relative pressure range of 0.003 to 0.3 . Pore volume and pores-size distribution were calculated according to the Barret-Joyner-Halenda (BJH) method, using data from the adsorption isotherm branch. The Harkins and Jura equation was used from calculating the thickness $t$ of the adsorbed layer on the pore walls at every $\mathrm{P} / \mathrm{P}_{\mathrm{o}}$. UV-vis diffuse reflectance spectra, in the range from $200-900 \mathrm{~nm}$, were used to determine the absorption properties and the band gap of the photocatalysts. The reflectance data was converted to the absorption coefficient $\mathrm{F}(\mathrm{R})$ values according to the Kubelka-Munk equation (37) being $F(R)$ equivalent to the absorption coefficient. The band gap was calculated by plotting the modified Kubelka-Munk function, $(\mathrm{F}(\mathrm{R}) \cdot \mathrm{E})^{0.5}$ versus $E$ the energy of exciting light and determining the band gap from where the tangent cuts the $\mathrm{x}$-axis (38).

\subsection{Degradation Trials}

As mentioned previously the photocatalytic activity tests were NO removal and self cleaning of solid surfaces. The NOx oxidation test was based on a continuous flow reactor where the concentration of $\mathrm{NO}$ and $\mathrm{NO}_{2}$ in the outlet gas was continuously monitored during the gas phase heterogeneous photocatalytic oxidation of NO in air by the tested catalyst. The procedure followed was a modification of the ISO standard (39) using recycled instead of a continuous flow, to be able to determine the kinetics of the decrease in the NOx content over time. For detailed description of the experimental procedure see (8). A kinetic approach was used establishing the reaction constants by different theoretic and experimental models.

The self-cleaning tests were designed to determine the discoloration of compounds on the surface of the photocatalytic material. Two different self-cleaning methods were preformed: on one hand, the UNI standard (40) as a basis, modified in some parts that evaluates the discoloration of Rhodamine B (red colored). On the other hand, the discoloration of a tobacco extract applied on the catalytic surface was evaluated. Tobacco extract was used for its complex mixture of organic compounds and for evaluating also the color of dirt most usually found in real construction materials (brown). The tobacco solution was produced by leaching tobacco in deionized water during 24 hours before filtering the solid material. The remaining tobacco solution was applied on the sample of the surface and let to evaporate leaving a brownish film on the surface.

The colour measurements where done directly on the surface of the sample by a portable spectrophotometer. The results were expressed according CIELAB colour coordinate system. This system is based on three colour coordinates named $\mathrm{L}^{*}, \mathrm{a}^{*}$ and $\mathrm{b}^{*}$ forming a three-dimensional space. $\mathrm{L}^{*}$ describes the brightness from black to white where 0 is black and 100 white, $a^{*}$ the colour from green (negative value) to red (positive value) and $\mathrm{b}^{*}$ from blue (negative value) to yellow (positive value). To assess the colour change of the specimens due to photocatalysis process the three coordinates $L^{*}, a^{*}$, and $b^{*}$ were registered before and after the exposure to UV irradiation. Also these coordinates were measured before addition of solution in order to have the reference of the clean initial colour.

Rhodamine B was selected for its low sensibility for UV-light, stability in a basic environment, high colorimetric sensibility and previous use in photocatalysts. The self-cleaning studies were also carried out investigated the discoloration of a tobacco extract applied on the catalytic surface. Tobacco extract was used for its complex mixture of organic compounds, as tar and nicotine, whose brownish color is more representative of most real dirt in reality. The tobacco solution was produced

TABLE 2. Experimental conditions for the evaluation of the photocatalytic activity by NOx oxidation, and self-cleaning activity for the studied catalysts

\begin{tabular}{lccc}
\hline Test & NOx oxidation & Rhodamine B & Tobacco \\
\hline Temperature $\left({ }^{\circ} \mathbf{C}\right)$ & 21 & 20 & 20 \\
Humidity $(\% \mathbf{R H})$ & 62 & 50 & 50 \\
Lamp & Philips Actinic BL $15 \mathrm{~W}$ 10 SLV & Philips PL-S 9W/2P BLB & Philips PL-S 9W/2P BLB \\
Irradiance $\left(\mathbf{W} / \mathbf{m}^{2}\right)$ & 10 & 5 & 5 \\
Catalyst load $\left(\mathbf{g} / \mathbf{m}^{2}\right)$ & 5.0 & 5.0 & 5.0 \\
Initial $\mathbf{~ N O ~ c o n c e n t r a t i o n ~ ( p p b v ) ~}$ & 1000 & - & - \\
Initial $\mathbf{~} \mathbf{O}_{2}$ concentration $(\mathbf{p p b v})$ & 50 & $1.368 \mathrm{E}^{-4}$ & - \\
Initial $\mathbf{R h B}$ concentration $\left(\mathbf{m o l} / \mathbf{m}^{2}\right)$ & - & - & 2.359 \\
Initial tobacco concentration $\left(\mathbf{g} / \mathbf{m}^{2}\right)$ & - & &
\end{tabular}


by leaching tobacco in deionized water during 24 hours before filtering the solid material. The remaining tobacco solution was applied on the sample of the surface and let to evaporate leaving a thin film of tobacco extract on the surface.

The photocatalytic activity of the studied catalysts was quantified under the same experimental conditions for all the catalysts. The parameters used for the NO oxidation, rhodamine $\mathrm{B}$ discoloration and tobacco discoloration are summarized in Table 2.

\section{RESULTS AND DISCUSSION}

In Figure 1, a BSE image of the mapping (EDX) of a transversal cut of the sample for catalyst A is given where it can be seen the distribution of elements corresponding to the typical ones for the mortar as well as the Ti. From it, it can be deduced that $\mathrm{TiO}_{2}$ did not penetrate into the mortar porous network. A compact homogeneous and well adhered layer of $\mathrm{TiO}_{2}$ on the surface of the mortar with a thickness of around $10 \mu \mathrm{m}$ was created.

\subsection{Constituents phases}

DRX results showed that catalysts $\mathrm{F}$ and $\mathrm{G}$ contained pure rutile, catalyst $\mathrm{A}$, a dominant anatase phase and a minor rutile phase, while the rest of the catalysts contained pure anatase, Figure 2. The paint samples also contained other crystallographic phases being additives that do not belong to the crystal phases of $\mathrm{TiO}_{2}$. It was confirmed that the exposure of the catalysts to water did not change the crystallographic phase composition, Figure 2.

The calcination of the catalysts led to a phase change from anatase to the thermodynamically favored rutile phase for both catalyst $\mathrm{A}$ and $\mathrm{S}-\mathrm{TiO}_{2}$. A pure rutile phase was formed for catalyst $\mathrm{A}$ and a mixture of anatase and rutile phases for $\mathrm{S}-\mathrm{TiO}_{2}$ after calcination. The rest of the annealed catalysts maintained their pure anatase phase even after the calcination at $800^{\circ} \mathrm{C}$. The shift to rutile was mentioned in the literature to occur at $700{ }^{\circ} \mathrm{C}$ resulting in a mixture of anatase and rutile.

\subsection{Crystal size and cristallinity degree}

The crystal sizes of the studied catalysts determined by the Scherrer's equation using the peak corresponding to the (101) plane for the anatase and (110) for the rutile phase, are given in table 3. It can be seen that for untreated catalysts the size of the particles goes for anatase between 9.1 and $22.9 \mathrm{~nm}$ being having bigger crystals for rutile. From the results, it can be deduced that the exposure of the catalysts to water do not change significantly the crystal sizes, which was in good agreement with (41). On the contrary, annealing of the catalysts increased the crystal size of both the anatase and the rutile phases. The anatase crystal sizes increased to $45.5-60.4 \mathrm{~nm}$, and the rutile crystals in catalyst A expanded from $37.8 \mathrm{~nm}$ to $66.6 \mathrm{~nm}$.
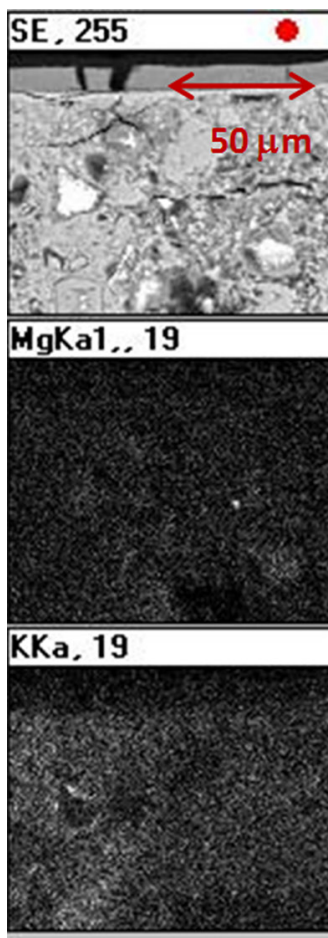

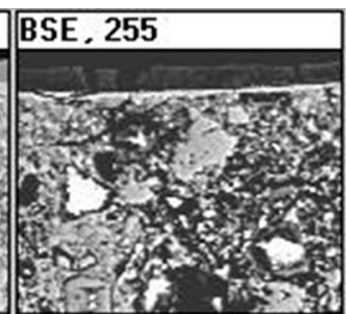

AlKa, 63

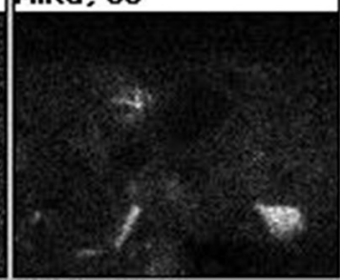

CaKa, 115

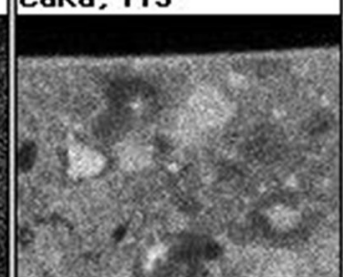

$0 K a, 26$

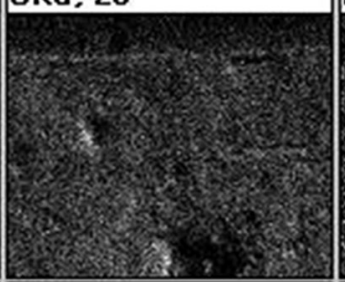

SiKa, 60

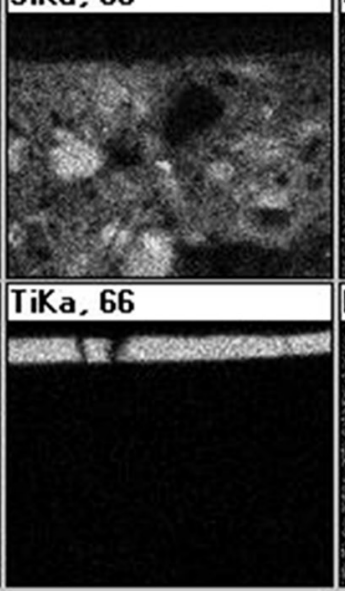

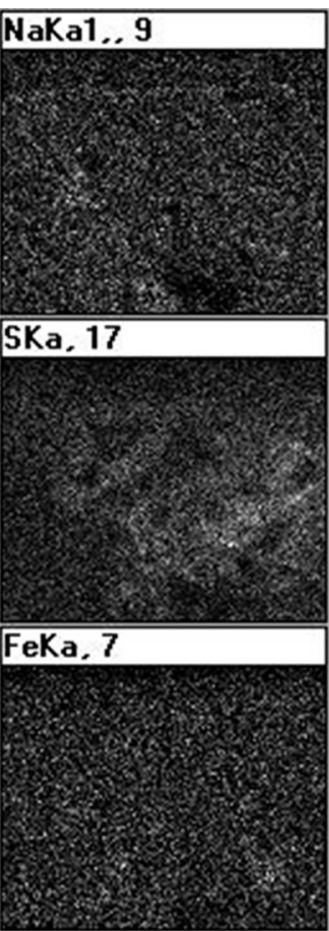

FIGURE 1. BSE image of the mapping (EDX) of a transversal cut of the sample for catalyst A. 


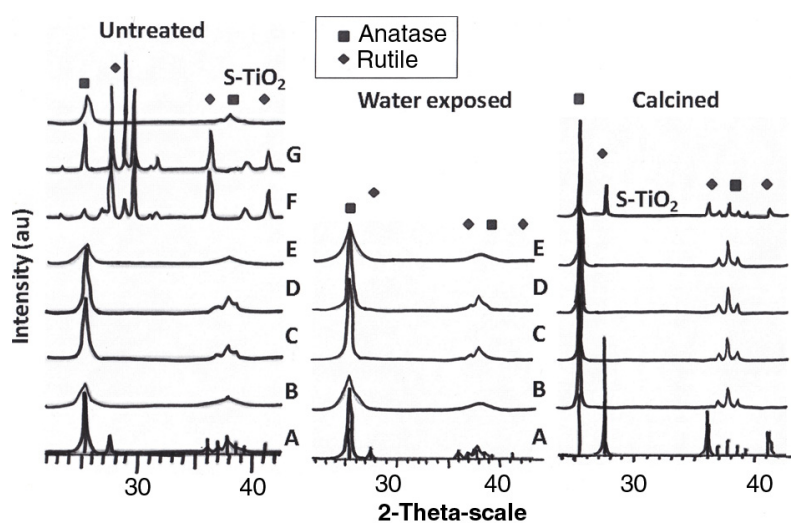

FIGURE 2. XRD spectra for the untreated, washed and calcined catalysts: A, B, C, D, E, F, G and $\mathrm{S}-\mathrm{TiO}_{2}$.

The full width at half maximum (FWHM), related with crystallinity and the size of grain), for the same peaks that those taken for determining the size, are given in table 4 . It could be said that smaller the FWHM of the peaks, better the crystallinity degree. From the variation in the FWHM, it can be deduced that water exposure increases slightly the degree of crystallinity, being this increase very important after calcinations of the catalysts.

\subsection{Optical properties}

\subsubsection{Absorbance $U V$-vis}

The absorbance spectra were performed for every catalyst without pretreatment and for two of the calcinated catalysts (A and $\mathrm{S}-\mathrm{TiO}_{2}$ ). All the catalysts absorbed light in the UV spectra, for some of them in the near UV and for $\mathrm{S}-\mathrm{TiO}_{2}$ into the visible light region slightly above $500 \mathrm{~nm}$, Figure 3 . The amount of absorbed light differed between the materials. The integrated absorbance over the wavelengths 200-900 nm proved a small difference between the studied catalysts with values from 212 to $280 \mathrm{~nm}$, (see table 5). In the photocatalytic experiments the UV light used emits radiation from 350 to $400 \mathrm{~nm}$ and therefore it was more proper to compare the absorption in the range of these wavelengths. This comparison give highest absorption for the catalysts: $\mathrm{F}, \mathrm{G}, \mathrm{S}-\mathrm{TiO}_{2}$ and the calcined samples of $\mathrm{S}-\mathrm{TiO}_{2}$ and catalyst $\mathrm{A}$ that absorbed in higher wavelengths compared to the rest of the catalysts. The absorption at higher wavelengths was justified by the XRD results that revealed the presence of rutile in these materials except for $\mathrm{S}_{-} \mathrm{TiO}_{2}$. The higher absorption of $\mathrm{S}-\mathrm{TiO}_{2}$ was regarded to the visible light absorption

TABLE 3. Crystal size for the untreated, water exposed and annealed catalysts, for the anatase (peak 101) and rutile (110) phases

\begin{tabular}{|c|c|c|c|c|c|c|}
\hline \multirow[b]{2}{*}{ Catalyst } & \multicolumn{3}{|c|}{ Anatase: Crystal size (nm) } & \multicolumn{3}{|c|}{ Rutile Crystal size (nm) } \\
\hline & Untreated & Water exposure & Calcined & Untreated & Water exposure & Calcined \\
\hline A & 22.9 & 23.2 & - & 37.8 & 38.3 & 66.6 \\
\hline B & 9.7 & 9.3 & 45.5 & - & - & - \\
\hline $\mathrm{C}$ & 19.3 & 18.7 & 51.4 & - & - & - \\
\hline $\mathrm{D}$ & 20.7 & 20.5 & 60.4 & - & - & 130.2 \\
\hline $\mathrm{E}$ & 9.1 & 8.5 & 57.2 & - & - & - \\
\hline $\mathrm{F}$ & - & & & 34.8 & & \\
\hline G & - & & & 52.7 & & \\
\hline $\mathrm{S}-\mathrm{TiO}_{2}$ & 14.6 & & 56.8 & - & & 79.1 \\
\hline
\end{tabular}

TABLE 4. FWHM for the untreated, water exposed and annealed catalysts, for the anatase (peak 101) and rutile (110) phases

\begin{tabular}{|c|c|c|c|c|c|c|}
\hline \multirow[b]{2}{*}{ Catalyst } & \multicolumn{3}{|c|}{ Anatase: FWHM } & \multicolumn{3}{|c|}{ Rutile: FWHM } \\
\hline & Untreated & Water exposure & Calcined & Untreated & Water exposure & Calcined \\
\hline A & 0.380 & 0.347 & - & 0.234 & 0.213 & 0.133 \\
\hline B & 0.891 & 0.703 & 0.191 & - & - & - \\
\hline $\mathrm{C}$ & 0.451 & 0.434 & 0.169 & - & - & - \\
\hline $\mathrm{D}$ & 0.422 & 0.391 & 0.144 & - & - & 0.0058 \\
\hline $\mathrm{E}$ & 0.954 & 0.760 & 0.152 & - & - & - \\
\hline $\mathrm{F}$ & - & & & 0.255 & & \\
\hline G & - & & & 0.169 & & \\
\hline $\mathrm{S}-\mathrm{TiO}_{2}$ & 0.600 & & 0.150 & - & & 0.11 \\
\hline
\end{tabular}




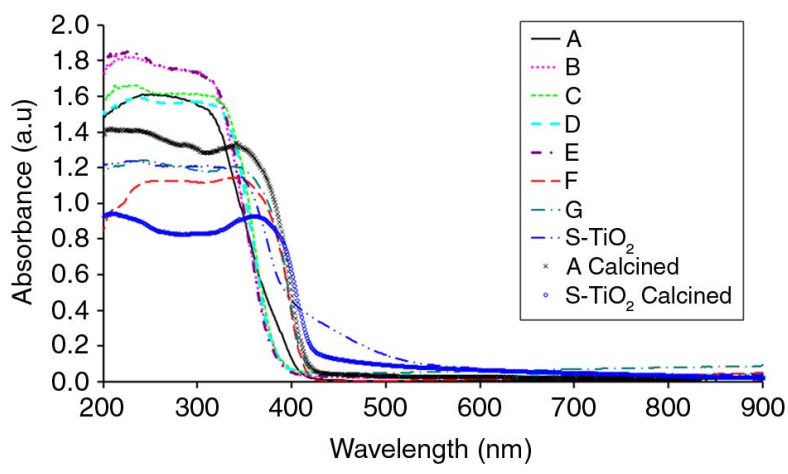

FIGURE 3. Absorbance spectra of the different photocatalysts.

properties caused by doping (S, C, N) (36). The visible light absorption was highest for $\mathrm{S}-\mathrm{TiO}_{2}$ having the highest absorption in the range $401-900 \mathrm{~nm}$.

\subsubsection{Band gap determination}

The band gap was calculated by plotting the modified Kubelka-Munk function, $(\mathrm{F}(\mathrm{R}) \cdot \mathrm{E})^{0.5}$ versus $E$ the energy of exciting light and determining the band gap from where the tangent cuts the $\mathrm{x}$-axis (37). The numerical values of the band gap for the untreated and calcined catalysts are given in Table 6.

Visible light detectable to human eye starts from $390 \mathrm{~nm}$ and the band gaps corresponding to visible light can be seen for the catalysts: F, G, S-TiO ${ }_{2}$ and the calcined samples of $\mathrm{S}^{-\mathrm{TiO}_{2}}$ and $\mathrm{A}$. This was in accordance with the highest absorbing catalysts in the range 350-400 $\mathrm{nm}$ given in Table 6 .

The band gap obtained for the different catalyst in function of their crystal size is given in Figure 4. First of all, it has to be remarked that the catalyst presented here are different materials even though all of them are $\mathrm{TiO}_{2}$ based. So, the typical trend of the band gap as a function of the particle size shoud not primarily

TABLE 5. Integrated UV-VIS absorbance of the studied catalysts (a.u nm)

\begin{tabular}{lcccc}
\hline Catalyst & $\begin{array}{c}\mathbf{3 5 0 - 4 0 0} \\
\mathbf{n m}\end{array}$ & $\begin{array}{c}\mathbf{2 0 0 - 4 0 0} \\
\mathbf{n m}\end{array}$ & $\begin{array}{c}\mathbf{2 0 0 - 9 0 0} \\
\mathbf{n m}\end{array}$ & $\begin{array}{c}\mathbf{4 0 1 - 9 0 0} \\
\mathbf{n m}\end{array}$ \\
\hline $\mathrm{A}$ & 23.7 & 248 & 253 & 5 \\
$\mathrm{~B}$ & 18.1 & 270 & 279 & 9 \\
$\mathrm{C}$ & 22.0 & 260 & 275 & 15 \\
$\mathrm{D}$ & 20.1 & 249 & 267 & 18 \\
$\mathrm{E}$ & 17.1 & 271 & 281 & 10 \\
$\mathrm{~F}$ & 44.7 & 209 & 222 & 13 \\
$\mathrm{G}$ & 46.6 & 228 & 263 & 35 \\
$\mathrm{~S}-\mathrm{TiO}_{2}$ & 38.9 & 220 & 273 & 53 \\
$\mathrm{~A} \mathrm{Calcined}$ & 52.1 & 255 & 274 & 19 \\
$\mathrm{~S}^{-\mathrm{TiO}_{2}}$ calcined & 42.9 & 174 & 212 & 38 \\
\hline
\end{tabular}

expected. On the other hand, QSE occur for semiconductor particles on the order of 1-10 nm in size, even though (42) found that for anatase, there was almost no variation of the band gap energy with size down to $7.5 \mathrm{~nm}$. In this research two catalysts could eventually experiment QSE: the powdered catalysts B and E, both slightly below $10 \mathrm{~nm}$ and both are having the highest band gap. Catalysts A, C and D, in their anatase phases, have band gaps higher than the theoretical value for this phase while the opposite takes place for $\mathrm{S}_{-} \mathrm{TiO}_{2}$. In the case of $\mathrm{S}-\mathrm{TiO}_{2}$, as it is a homemade material it is possible to known the reason: it is a codoped catalyst. Rutile catalyst, having higher sizes are all of them very close to the theoretical values, with the exception of calcined $\mathrm{S}-\mathrm{TiO}_{2}$, red shifted due again to doping. After annealing, both catalysts exhibited a reduction in the band gap. In the case of catalyst A anatase converts to rutile, and the corresponding band gap is the theoretical one for rutile.

\subsection{Microstructure}

Figure. 5 presents the N2 adsorption isotherms of the catalysts without and after the water treatment and annealing. For untreated materials, catalyst B and $\mathrm{E}$, the isotherms are of Type II, indicating an indefinite multi-layer formation after completion of the monolayer and are found in adsorbents with a wide distribution of pore sizes. The rest of catalysts present Type III isotherms, obtained when the amount of gas adsorbed increases without limit as its relative saturation approaches unity. The exposure of the catalysts to water did not show an influence on the isotherms, except for catalyst A where adsorption was higher at the highest partial pressures than in the case of untreated catalyst. The heat treatment of the catalysts: $\mathrm{A}, \mathrm{D}$ and $\mathrm{S}-\mathrm{TiO}_{2}$ to $800^{\circ} \mathrm{C}$ led to a collapse of the porous structure and a decrease in the adsorbed volume indicating a less porous material. This collapse due to heating was also proved by Puddu et al. (35).

TABLE 6. Calculated band gap for the studied catalysts (calcined samples to $800^{\circ} \mathrm{C}$ )

\begin{tabular}{lcc}
\hline Catalyst & $\begin{array}{c}\text { Band gap } \\
(\mathbf{e V})\end{array}$ & $\begin{array}{c}\text { Corresponding wavelength } \\
(\mathbf{n m})\end{array}$ \\
\hline $\mathrm{A}$ & 3.30 & 376 \\
$\mathrm{~B}$ & 3.36 & 369 \\
$\mathrm{C}$ & 3.29 & 377 \\
$\mathrm{D}$ & 3.30 & 376 \\
$\mathrm{E}$ & 3.35 & 370 \\
$\mathrm{~F}$ & 3.02 & 411 \\
$\mathrm{G}$ & 3.01 & 412 \\
$\mathrm{~S}-\mathrm{TiO}_{2}$ & 3.06 & 405 \\
$\mathrm{~A} \mathrm{calcined}$ & 3.01 & 412 \\
$\mathrm{~S}^{-\mathrm{TiO}_{2}}$ calcined & 2.93 & 423 \\
\hline
\end{tabular}



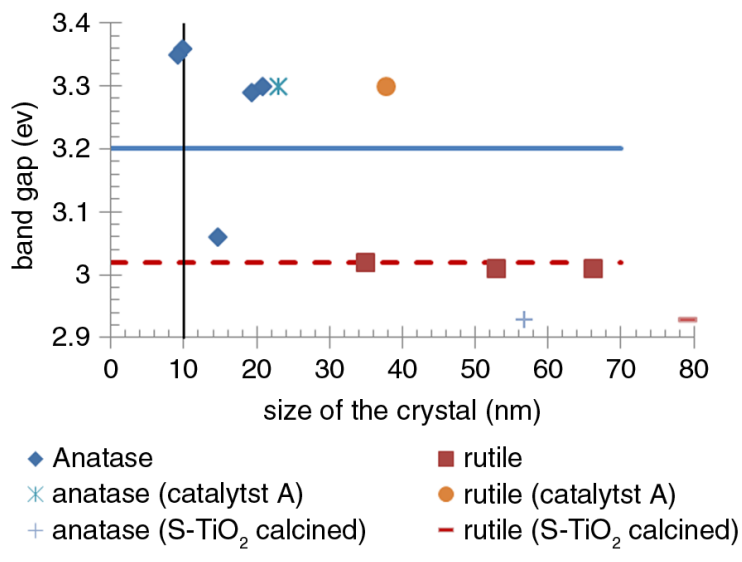

FIGURE 4. Band gap as a function of the crystal size. Horizontal continuous and discontinuous lines are the theoretical band gap values for anatase and rutile respectively.

The pore size distribution (Figure 6), indicates that catalysts B, C, D and E presents a type of distribution with a maximum, at very small sizes for $\mathrm{B}$ and $\mathrm{E}$ (around $2 \mathrm{~nm}$ ) and at around $12 \mathrm{~nm}$ for catalysts $\mathrm{C}$ and $\mathrm{D}$. Catalyst $\mathrm{A}$ presents a monotonic trend growing as the size increase and all the porosity for $\mathrm{S}-\mathrm{TiO}_{2}$ is below $20 \mathrm{~nm}$. When submitted to water, the pore volume and average pore diameter were neither affected except in the case of catalyst
A, that increased the amount of bigger pores with a maximum at around $85 \mathrm{~nm}$. This change could be due to the more tight packing of particles causing formation of intra particle space in the measuring range of $\mathrm{N}_{2}$ adsorption. Pore size distribution after calcination of the catalysts demonstrated a total collapse of the porous network. The annealing dramatically decreased the pore volume for catalysts A, D and $\mathrm{S}-\mathrm{TiO}_{2}$ from 0.17 to $0.022 \mathrm{~cm}^{3} / \mathrm{g}, 0.31$ to $0.041 \mathrm{~cm}^{3} / \mathrm{g}$ and 0.062 to $0.0031 \mathrm{~cm}^{3} / \mathrm{g}$ respectively.

In table 7, a summary or these results is presented, where the BET area $S_{B E T}$ is also given. Highest specific surface area $S_{\mathrm{BET}}$ was found for the catalysts $B$ and $E$ with areas above $300 \mathrm{~m}^{2} / \mathrm{g}$, well in correspondence with their small crystal size. In agreement with the behavior on crystal size, the water treatment did not produce any significant change in the BET area of the studied catalysts (Figure 7). The heat treatment reduced the $\mathrm{S}_{\mathrm{BET}}$ surface to $15 \%$ for catalyst $\mathrm{A}$ and $10 \%$ for catalyst D compared to the surface area of the untreated catalyst.

\subsection{Photocatalytic Efficiency}

The photocatalytic activity expressed as NOx concentration ( $\mathrm{NO}$ and $\mathrm{NO}_{2}$ ) over time for the different studied catalysts is given in figure 8 . It was revealed that the presence of the catalyst reduce

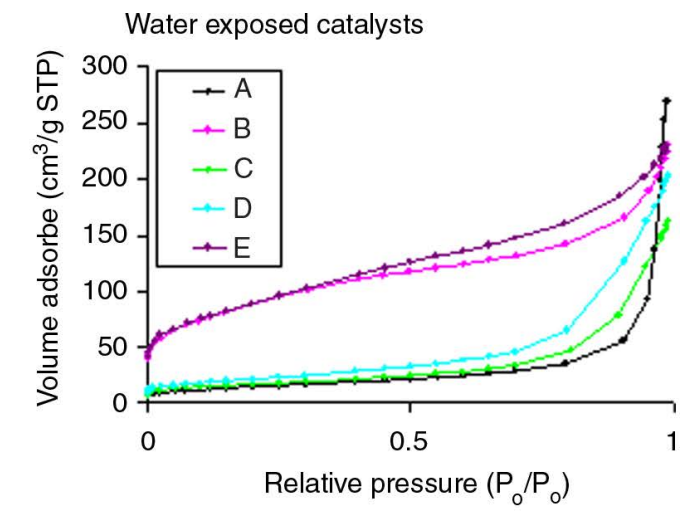

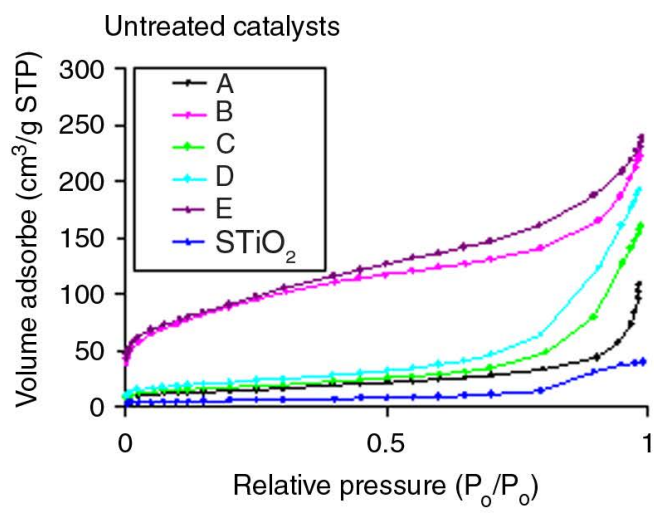

Calcined catalysts

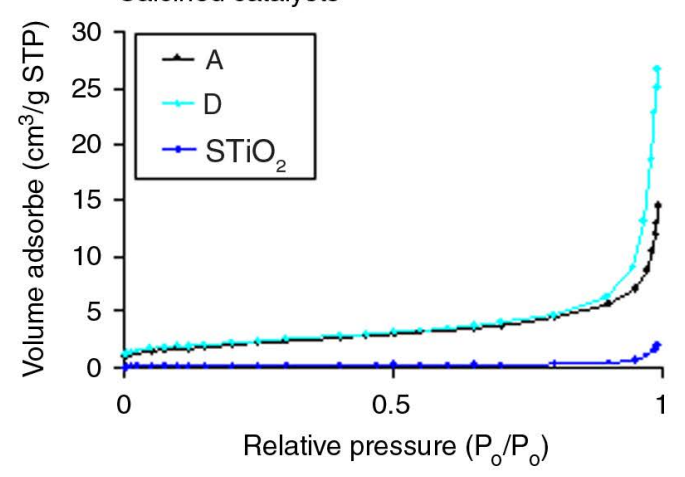

FIGURE 5. Isotherm diagrams of the studied catalyst before and after washing with deionised water and after calcination. (The $\mathrm{S}$-TiO 2 catalyst was not washed). For the units of the Y axis, the volume absorbed in Standard Temperature and Pressure conditions. 

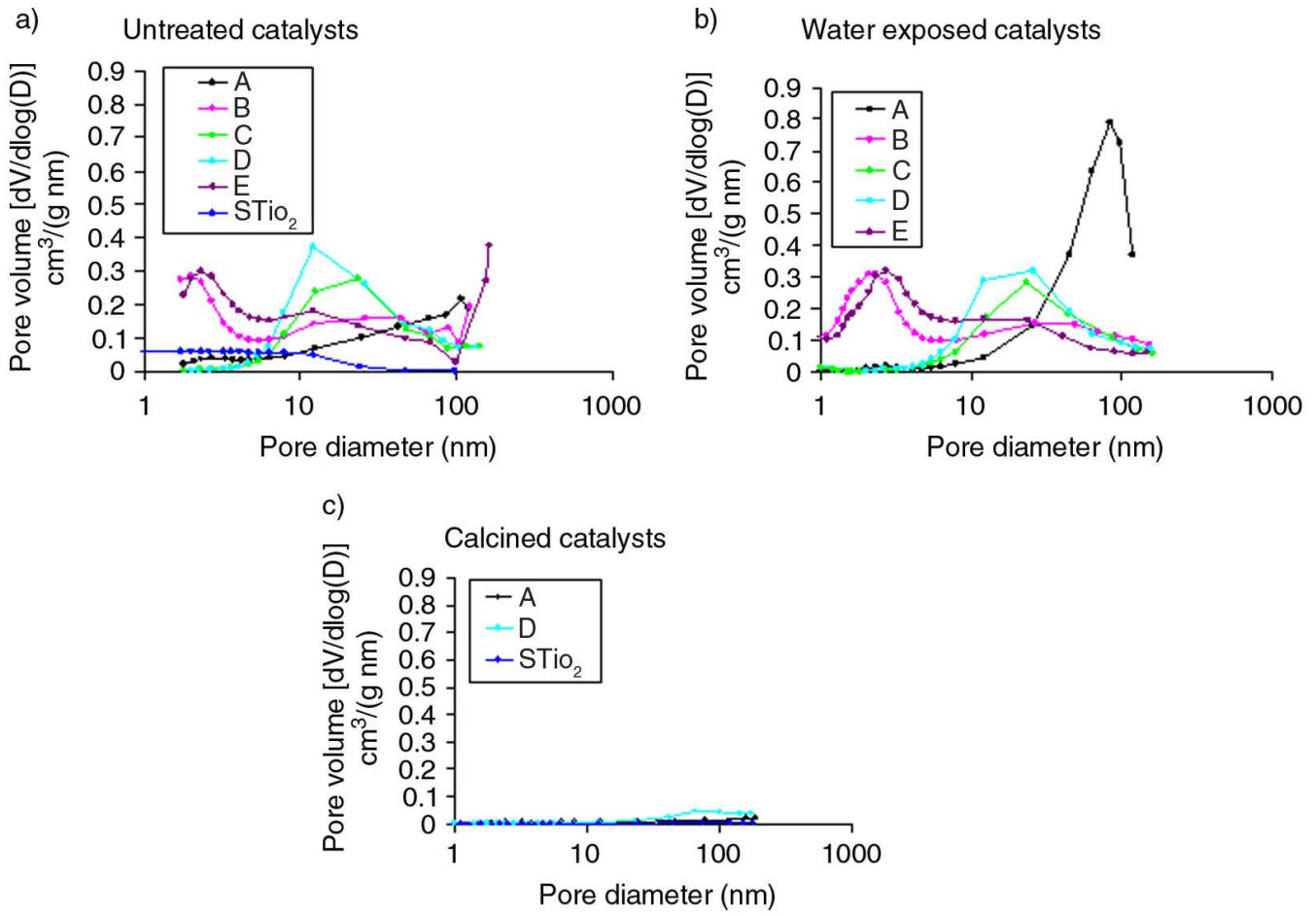

FIGURE 6. Pore diameter distribution for the untreated catalysts. a) Untreated catalysts, b) washed catalysts, c) calcined catalysts.

the concentration of $\mathrm{NO}$ over time compared to an inactive sample not containing catalyst. The catalysts $\mathrm{F}, \mathrm{G}$ and $\mathrm{S}-\mathrm{TiO}_{2}$ did not demonstrate photocatalytic activity. The concentration of NO after 120 minutes of radiation and exposure to the photocatalytic active materials was reduced from $1000 \mathrm{ppb}$ to
39-175 ppb. The highest NO oxidation rate was seen for catalyst $\mathrm{B}$ that also demonstrated the highest formation of $\mathrm{NO}_{2}$. The annealing of the catalysts $\mathrm{A}$ and the home made $\mathrm{S}-\mathrm{TiO}_{2}$ decreased the activity for the catalyst $\mathrm{A}$ and no significant change was seen for the $\mathrm{S}-\mathrm{TiO}_{2}$ being considered as inactive.

TABLE 7. Microstructure parameters for the different catalysts before and after the treatments

\begin{tabular}{llccc}
\hline Catalyst & \multicolumn{1}{c}{ Treatment } & SBET $\left(\mathbf{m}^{2} / \mathbf{g}\right)$ & Pore volume $\left(\mathbf{c m}^{3} / \mathbf{g}\right)^{\mathbf{a}}$ & Pore diameter $(\mathbf{n m})^{\mathbf{b}}$ \\
\hline $\mathrm{A}$ & Untreated & 49.9 & 0.167167 & 13.38 \\
& Exposed to water & 51.49 & 0.416103 & 32.32 \\
& Calcined & 7.27 & 0.02234 & 12.29 \\
$\mathrm{~B}$ & Untreatedw & 311.8 & 0.350614 & 4.51 \\
& Exposed to water & 311.1 & 0.356796 & 4.58 \\
$\mathrm{C}$ & Untreated & 60.3 & 0.248026 & 16.44 \\
& Exposed to water & 59.31 & 0.250779 & 16.91 \\
$\mathrm{D}$ & Untreated & 75.8 & 0.304871 & 16.08 \\
& Exposed to water & 76.14 & 0.313132 & 16.44 \\
& Calcined & 7.84 & 0.041337 & 21.09 \\
$\mathrm{E}$ & Untreated & 320.2 & 0.369515 & 4.61 \\
& Exposed to water & 313.1 & 0.354598 & 4.52 \\
$\mathrm{~S}-\mathrm{TiO}_{2}$ & Untreated & 24.5 & 0.061500 & 13.87 \\
& Calcined & 0.505 & 0.003102 & 24.59 \\
\hline
\end{tabular}

\footnotetext{
${ }^{a}$ Single Point Total Pore Volume of pores less than $218.16 \mathrm{~nm}$ Diameter at P/Po 0.99114583.

${ }^{\mathrm{b}}$ Average Pore Diameter (4V/A by BET).
} 


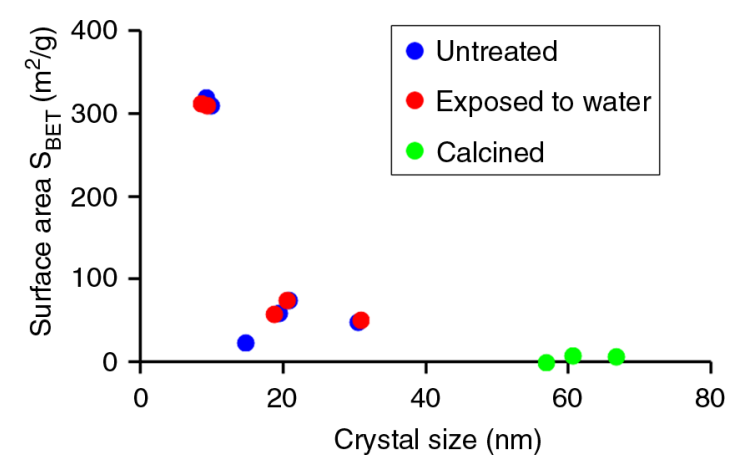

FIGURE 7. $\mathrm{S}_{\mathrm{BET}}$ area as a function of the crystal size.

The results for the rhodamine $\mathrm{B}$ and tobacco degradation were expressed as "a" and $v=\sqrt{a^{2}+b^{2}}$ and, respectively as a function of the irradiation time for the studied catalysts before and after the heat treatment. The results are given in Figure 9.

The photocatalytic activity of the different tested catalysts determined by rhodamine B degradation over time demonstrated that the presence of the catalyst reduced in higher content the concentration of rhodamine B over time compared to the sample not contained catalyst. The decrease in colour of the sample not containing catalysts was caused by photo-oxidation of the colorant. Very low activity was seen for the catalysts $\mathrm{F}, \mathrm{G}$ and $\mathrm{S}-\mathrm{TiO}_{2}$ concluding low or absence of photocatalytic activity. The annealing of catalyst $\mathrm{A}$ and $\mathrm{S}-\mathrm{TiO}_{2}$ reduces the reaction rate indicating a lower activity for both catalysts. The photocatalytic activity determined by tobacco degradation over time demonstrated that the presence of the catalyst reduce in higher content
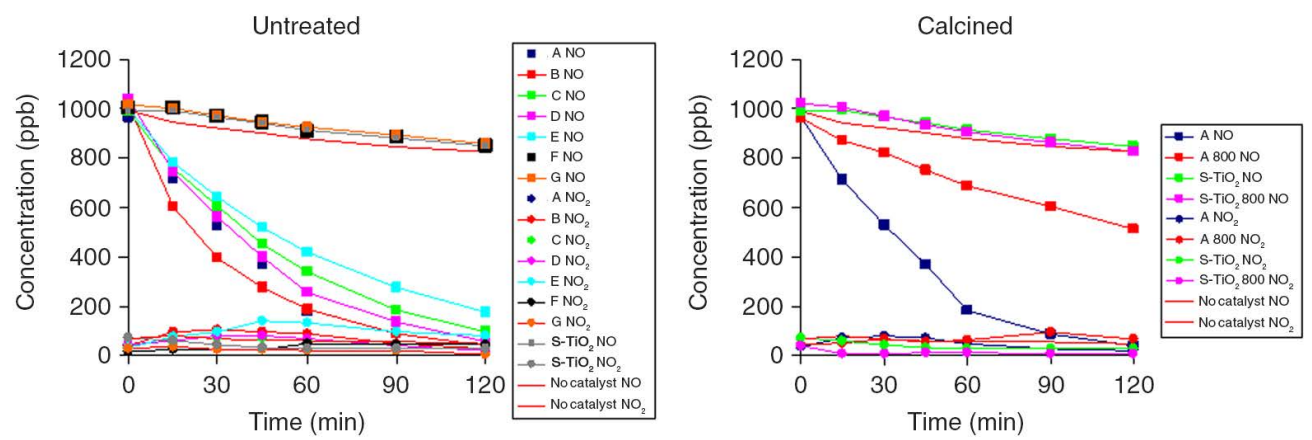

FIGURE 8. Photocatalytic activity expressed as NOx concentration $\left(\mathrm{NO}\right.$ and $\left.\mathrm{NO}_{2}\right)$ over time for the different studied catalysts.
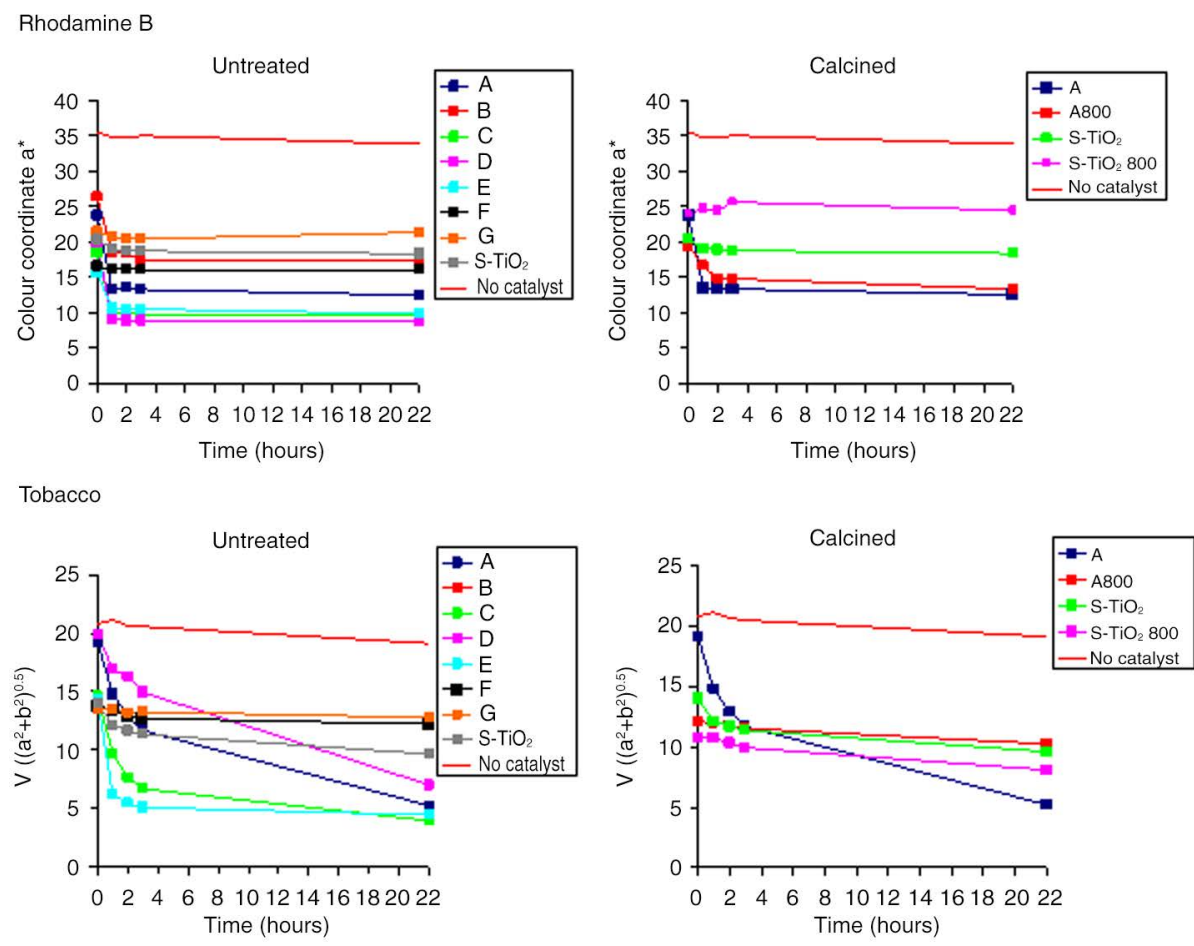

FIGURE 9. Photocatalytic activity results for the rhodamine B and tobacco degradation. 
the concentration of tobacco over time compared to the sample not containing catalyst. Very low activity was seen for the catalysts $\mathrm{F}$ and $\mathrm{G}$ concluding low or absence of photocatalytic activity. The annealing of catalyst $\mathrm{A}$ and $\mathrm{S}-\mathrm{TiO}_{2}$ reduced the reaction rate indicating a lower activity for both catalysts.

The NO oxidation kinetics was estimated by a first order reaction, presented in its integrated form in Equation [2].

$$
C=C_{0} \cdot e^{-k_{N O} \cdot t}
$$

where: $\mathrm{C}_{0}$ is the initial $\mathrm{NO}$ concentration (ppb) $\mathrm{t}$ the time $(\mathrm{min})$ and $\mathrm{k}_{\mathrm{NO}}$ the reaction rate constant $\left(\mathrm{min}^{-1}\right)$.

For self-cleaning the expression of the degradation was fitted also to simple elemental order reactions of $\mathrm{n}^{\text {th }}$ order [equation 3]. The best fitting of the results to this equation resulted to be of $n=50$ for rhodamine and $n=5$ for tobacco. It is important to remark that these values for $n$, especially for rhodamine B do not have any physical sense and therefore the values for " $k$ " obtained cannot be considered as reaction kinetic constants but empirical fitting constants that allow making comparison in a simple manner.

$$
C=\left(\frac{1}{(n-1) \cdot\left(k \cdot t+\frac{1}{(n-1) \cdot C_{0}^{(n-1)}}\right)}\right)^{(1 /(n-1))}
$$

For rhodamine B, The efficiency for catalysts $\mathrm{F}$, $\mathrm{G}$, the home made catalyst $\mathrm{S}-\mathrm{TiO}_{2}$ calcined at $800^{\circ} \mathrm{C}$ could not be adjusted to equation 3 .

The constants " $\mathrm{k}$ " so obtained are given in figure 10 and the variance explained, $R^{2}$, is given in Table 8 . It is remarkable that the same catalyst demonstrated different activity depending on the test used for its evaluation. Catalyst B was the most active catalyst determined by the $\mathrm{NO}$ oxidation and the tobacco discoloration tests. The opposite trend was seen when the activity was determined by the rhodamine $\mathrm{B}$ degradation where catalyst $\mathrm{B}$ was the less active material. The annealing of catalyst A demonstrates an important decrease in activity both for NO oxidation and for the tobacco discoloration, while the discoloration of rhodamine B was not affected
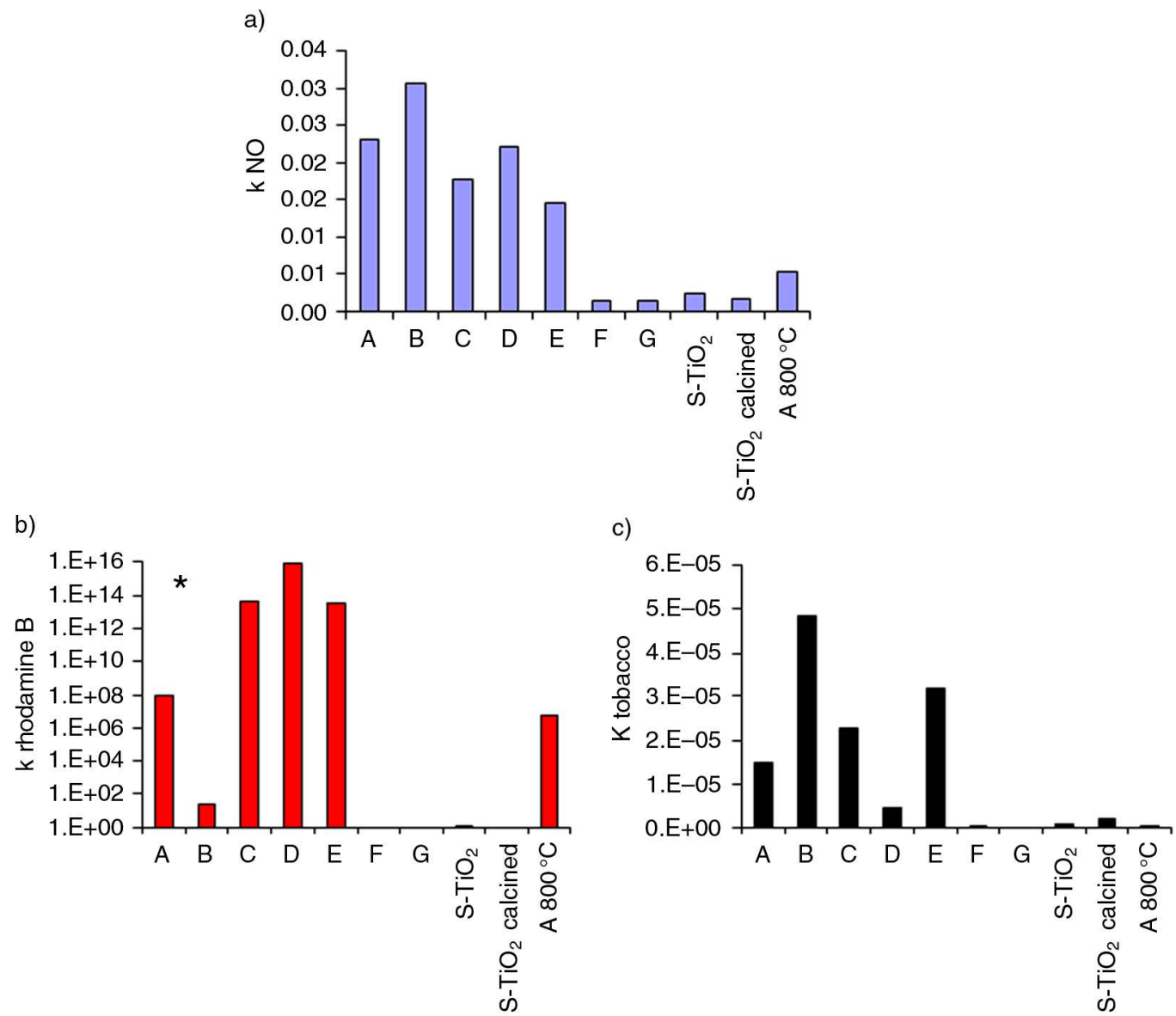

FIGURE 10. Comparison of the photocatalytic efficiency between the studied catalysts determined by a) NO oxidation, b) rhodamine $\mathrm{B}$ discoloration and c) tobacco discolouration. *The $\mathrm{k}$ values of the rhodamine $\mathrm{B}$ discoloration are multiplied by $1.10^{65}$ to achieve values above 1 for the logarithmic scale of the graph. 
TABLE 8. Variance explained, $\mathrm{R}^{2}$ in the different fittings of the results to equation 3

\begin{tabular}{lccc}
\hline Catalyst & $\begin{array}{c}\text { Fitting } \mathbf{~ N O} \mathbf{n}=\mathbf{1} \\
\mathbf{R}^{\mathbf{2}}\end{array}$ & $\begin{array}{c}\text { Fitting } \mathbf{R} \mathbf{h B} \mathbf{n}=\mathbf{5 0} \\
\mathbf{R}^{\mathbf{2}}\end{array}$ & $\begin{array}{c}\text { Fitting Tobacco } \mathbf{n}=\mathbf{5 0} \\
\mathbf{R}^{\mathbf{2}}\end{array}$ \\
\hline $\mathrm{A}$ & 0.994 & 0.998 & 0.980 \\
$\mathrm{~B}$ & 0.995 & 0.995 & 0.997 \\
$\mathrm{C}$ & 0.998 & 0.993 & 0.988 \\
$\mathrm{D}$ & 0.998 & 0.881 & 0.979 \\
$\mathrm{E}$ & 0.999 & 0.994 & 0.395 \\
$\mathrm{~F}$ & 0.968 & - & 0.362 \\
$\mathrm{G}$ & 0.991 & - & 0.902 \\
$\mathrm{~S}-\mathrm{TiO}_{2}$ & 0.963 & 0.823 & 0.751 \\
$\mathrm{~S}-\mathrm{TiO}_{2}$ calcined & 0.988 & - & 0.995 \\
$\mathrm{~A} \mathrm{calcined}$ & 0.996 & 0.969 & 0.992 \\
\hline
\end{tabular}

by the annealing. The annealing of $\mathrm{S}_{-} \mathrm{TiO}_{2}$ decreases the activity for NO oxidation, but increased for the tobacco discoloration.

The so obtained constants are going to be used from now to express the photocatalytic activity

\subsection{Influence of the properties of the catalysts on the activity}

The influence of the crystallographic properties of the catalysts on the photocatalytic activity depending on the crystal size of both anatase and rutile is given in Figures 11 and 12 respectively. No clear relation has been deduced between the activity and the size of the crystals, neither for anatase or rutile, even though for pure anatase a trend increasing the activity when increasing the size of crystal is noticeable, mainly for Rhodamine B. The majority of the pure anatase phase catalysts had better activity than pure rutile catalysts for the NO oxidation and tobacco discoloration.

The crystalline degree expressed as Full Width at Half Maximum (FWHM) of the diffraction peaks, for anatase and rutile, and its influence of the photocatalytic activity for NOx oxidation and rhodamine $\mathrm{B}$ and tobacco discoloration is given in figure 12, where it can be seen that even though a clear relationship cannot be made, the tendency is to increase the efficiency as cristallinity decrease.

Anatase and rutile were expected to exhibit a synergetic effect explained by the fact that rutile acts as an electron sink by receiving electrons produced by the charge separation on the anatase phase that inhibits recombination of electrons and holes in the bulk allowing them to migrate to the surface (35). However, this effect was not detected in these results. The catalysts containing both anatase and rutile (points joined in the graphs through two headed arrows) were not more efficient than that containing pure anatase. As a general trend, pure rutile demonstrated the lesser active behavior. The phase transfer from anatase to rutile during calcination caused a drop in photocatalytic activity explained as due to accelerated growth of crystallites by provided heat during the phase transfer leading to the reduction of the surface area.
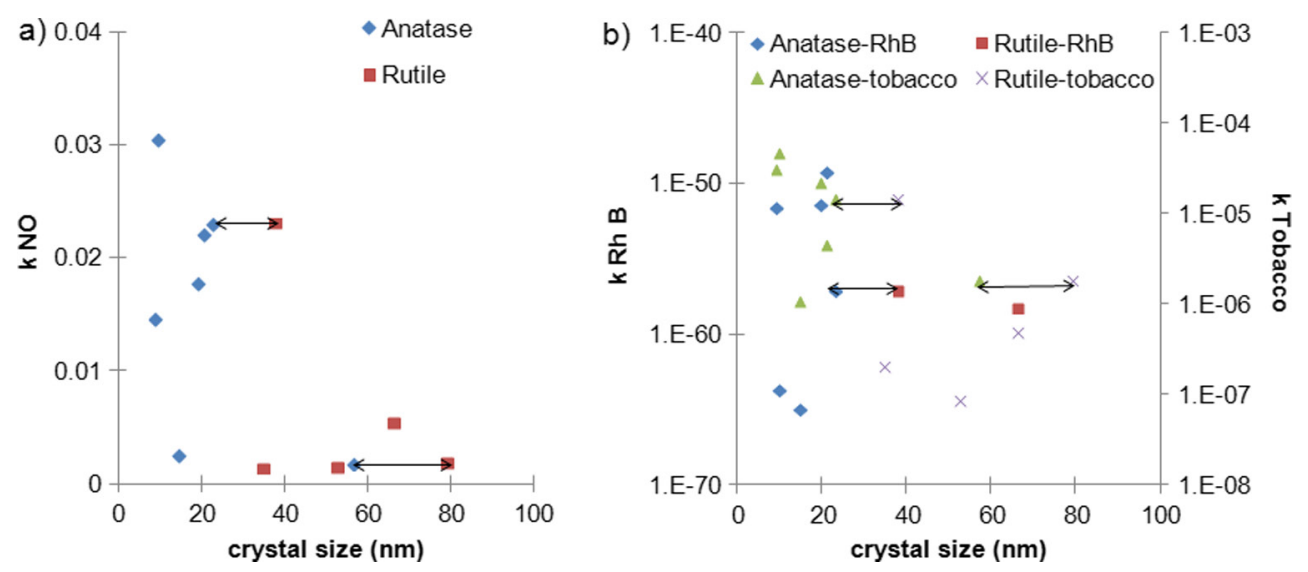

FIGURE 11. Influence of the crystal size of anatase and rutile on the photocatalytic degradation of a) NO and b) rhodamine $\mathrm{B}$ and tobacco. Two headed arrows join the points corresponding to the same catalyst composed of anatase and rutile. 

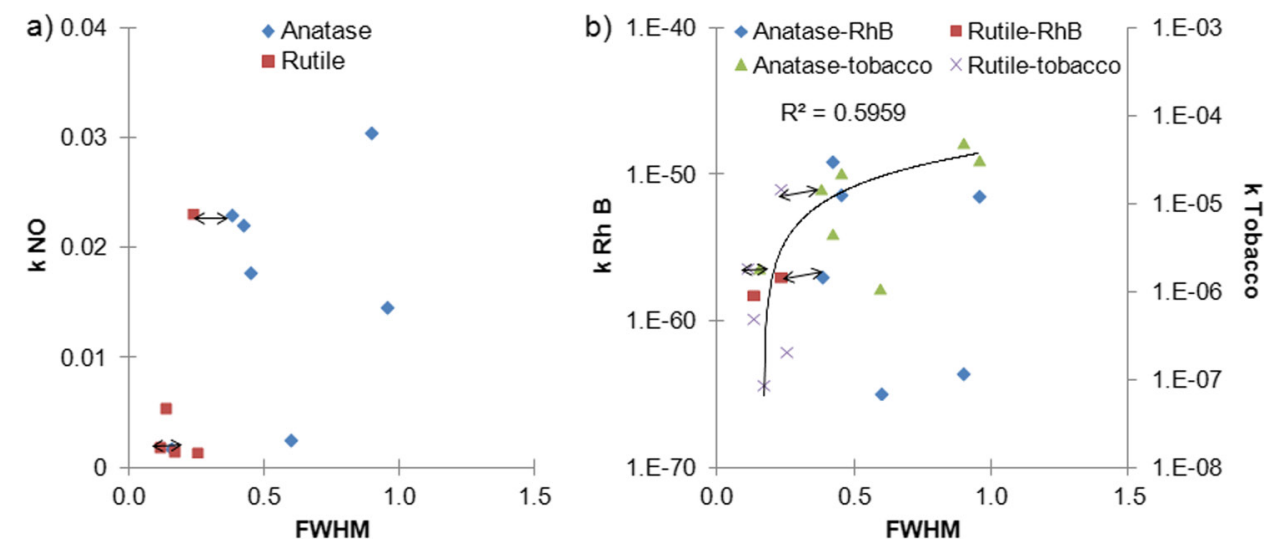

FIGURE 12. Influence of the FWHM (full width height medium) of anatase and rutile on the photocatalytic degradation of a) NO and b) rhodamine B and tobacco. Two headed arrows join the points corresponding to the same catalyst composed of anatase and rutile.
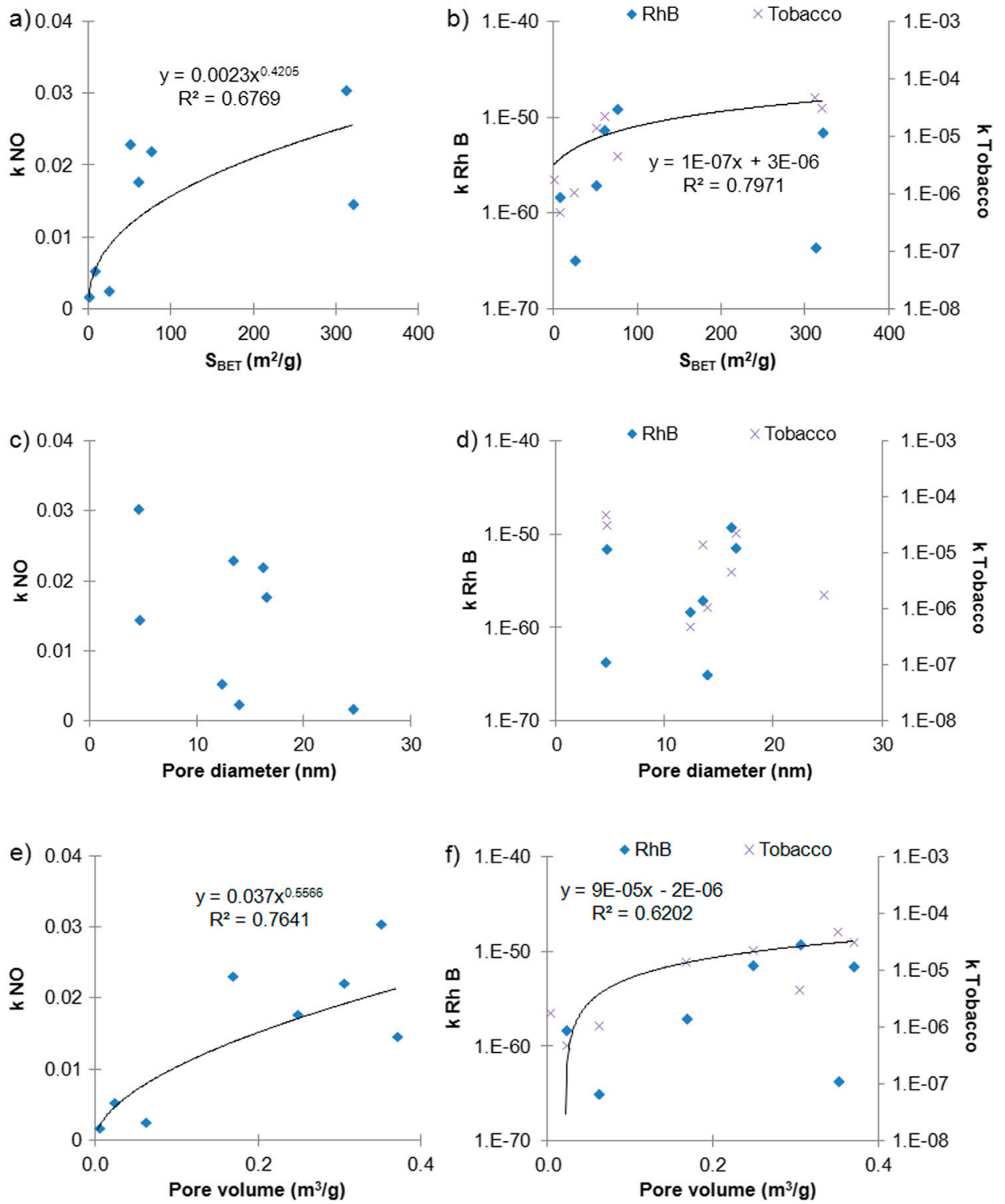

FIGURE 13. Influence of several microstructure properties of the catalysts on the $\mathrm{k}$ for NO, rhodamine B and tobacco: a-b) specific surface area $\mathrm{S}_{\mathrm{BET}}, \mathrm{c}-\mathrm{d}$ ) pore diameter and $\mathrm{e}-\mathrm{f}$ ) pore volume. 
$14 \cdot \mathrm{N}$. Bengtsson et al.
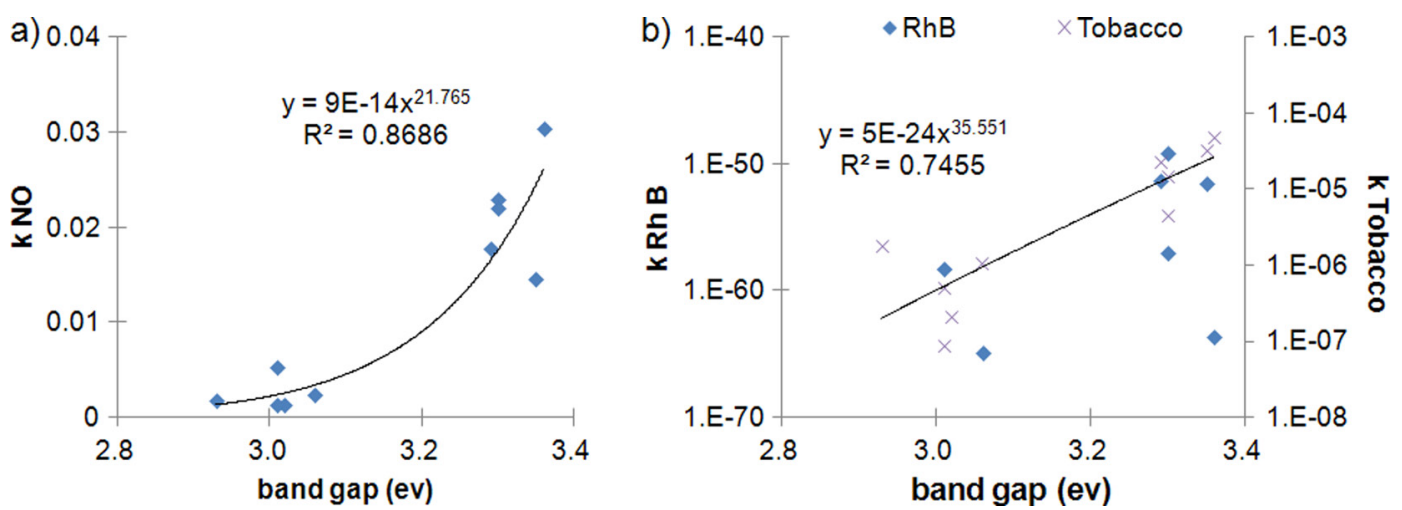

FIGURE 14. The influence of the band gap on the photocatalytic oxidation of a) NO and b) discoloration of rhodamine B and tobacco.
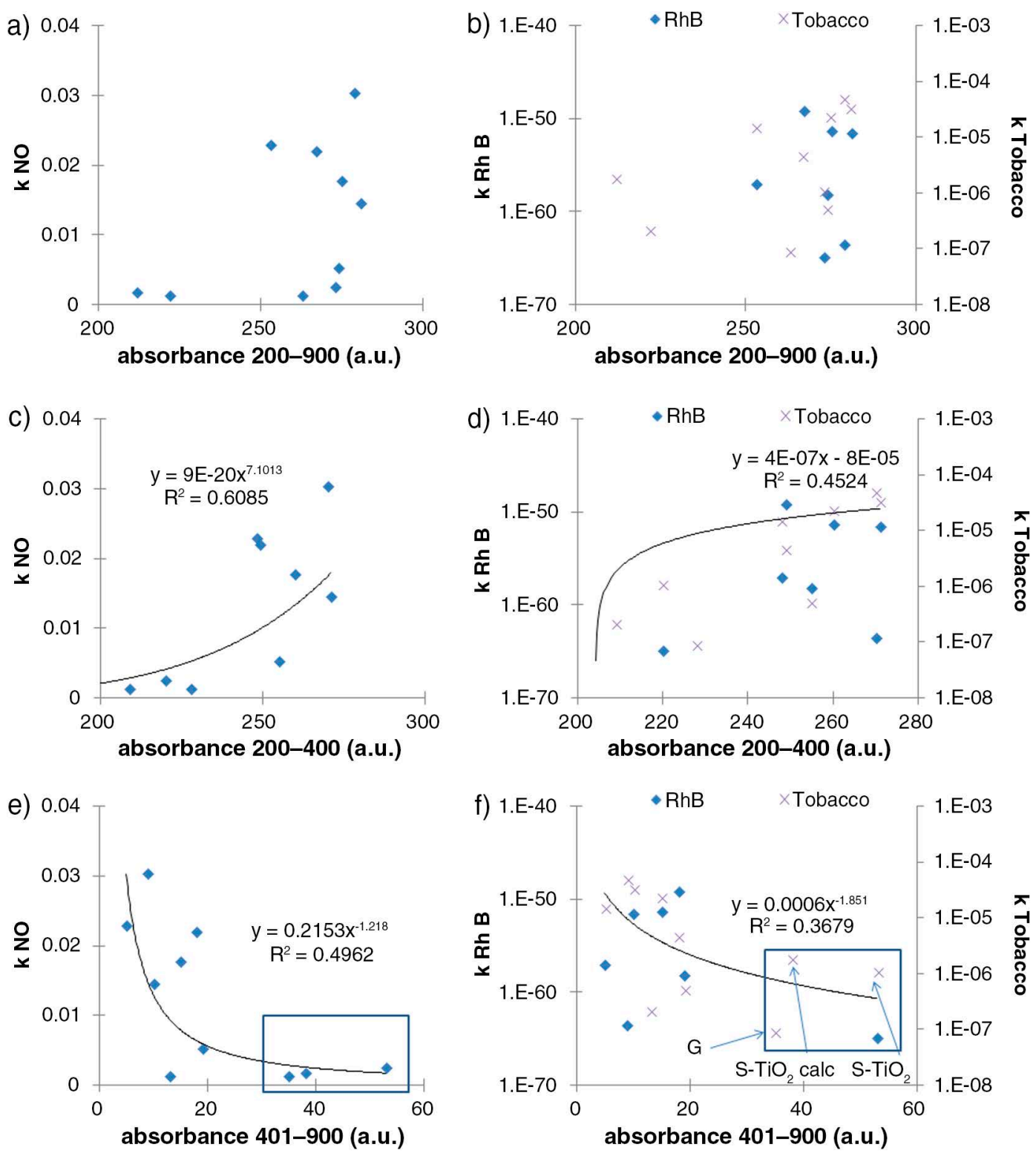

FIGURE 15. Influence of the absorbance of photons on the photocatalytic oxidation of NO, rhodamine B and tobacco discoloration. The type of test and the integration range of wavelengths are: a) NO-200-900 nm b) Rhodamine B and tobacco $200-900 \mathrm{~nm}$ c) NO-200-400 nm d) Rhodamine B and tobacco 200-400 nm e) NO-401-900 nm f) Rhodamine B and tobacco 401-900 nm. 
The influence of the microstructure properties of the catalysts in the values of efficiency expressed as k's are presented in figure $13(a-f)$. Specific surface area $S_{\mathrm{BET}}$ was demonstrated to have a positive influence on the photocatalytic activity, for NOx (potential trend) and tobacco (linear trend). For Rhodamine B a relationship was not found. The pore diameter do not seems to be very influential even though it seems to be a negative linear trend for $\mathrm{NO}$, while for the total pore volume, $\mathrm{m}^{3} / \mathrm{g}$, the trends are quite similar than for the BET area.

Concerning band gap, the NO oxidation and tobacco discoloration demonstrated that an increase in bad gap increased the photocatalytic activity with the best fitting to potential relationships for $\mathrm{NO}$ oxidation and for tobacco, while no relation was found for Rhodamine (Figure 14). It was expected a high influence of the band gap of the catalysts on the photocatalytic activity; However, a smaller band gap permit the catalyst to absorb less energetic photons of longer wavelengths taking advantage of light in a wider spectrum of wavelengths. However, the results obtained in this research are not as surprising as UV light was used with sufficient energy to activate all the catalysts; so, as higher the band gap, higher red-ox power of the catalysts.

The radiation source emitted wavelengths between 340 to $400 \mathrm{~nm}$ corresponding to band gap energies in the range of 3.1 to $3.65 \mathrm{eV}$ indicating that the catalysts with band gap energies below 3.1 $\mathrm{eV}$ were not absorbing the full spectra of the light source. On the other hand a higher band gap might result in higher reduction or oxidation power for the photo generated electrons and holes that could explain the increase in activity.

The influence of the absorbance of photons by the catalysts for NO oxidation, rhodamine B and tobacco discoloration is presented in figure 15 . The absorbance is given as the integrated number of photons absorbed by the photocatalytic material in the whole range registered covering both the ultraviolet and visible spectra, $200-900 \mathrm{~nm}$, in the range of UV-light spectra $200-400 \mathrm{~nm}$ and in the visible spectra $401-900 \mathrm{~nm}$.

The absorbance in the wave lengths $200-400 \mathrm{~nm}$, corresponding to UVA with enough energy to activate the studied catalysts demonstrated that an increase in absorbance increased the photocatalytic activity for the NO oxidation and tobacco discoloration (Figure $15 \mathrm{c}-\mathrm{d}$ ), in accordance with the behavior in relation with the band gap. Increases in absorbance in the visible light spectra decreased the activity for NO oxidation and tobacco discoloration, (figure $15 \mathrm{e}-\mathrm{f}$ ). The increased absorbance in the full spectra including ultraviolet and visible light enhanced the oxidation of NO and the discoloration of rhodamine B and tobacco, Figure $15 \mathrm{a}-\mathrm{b}$. It has to be pointed out that much more photons in the UV region were absorbed by all the catalysts, including that specified as improved for visible light $\left(\mathrm{S}-\mathrm{TiO}_{2}\right.$, catalyst $\left.\mathrm{G}\right)$, that in fact presented a reduced band gap and absorbed more protons in visible light than the others, (points marked inside a square in figures $15 \mathrm{e}-\mathrm{f}$ ).

The fact that no clear trends are found for Rhodamine B could be attributed to the fact that degradation of $\mathrm{RhB}$ dye follows two competitive processes such as $\mathrm{N}$-deethylation and destruction of conjugated structure $(43,44,45)$. Therefore, for these different catalysts, the degradation mechanisms seem to be dependent on the catalysts.

\section{CONCLUSIONS}

This work has evaluated the effect of the properties of the photocatalyst on the efficiency for degrading NOx and self cleaning (Rhodamine B and Tobacco extract). The efficiency has been compared on the basis of a constant $\mathrm{k}$ that for NO oxidation has the meaning of the kinetic constant for a first order reaction, while for self-cleaning are just empirical fitting constants without any other physical meaning, having obtained the following conclusions:

- The photocatalytic efficiency is dependent of the type of contaminant removed; the most active catalysts for one specific contaminant might be or not the least active for other compounds. So, there not seem to be "a universal best catalyst" for every contaminant. Therefore, from one isolated characteristic of a photocatalyst no general conclusions of its expected behavior can be extracted.

- In this research NO oxidation and tobacco extract follow similar trends according to most of the parameters studied; however, no clear relations have been found for Rhodamine B, which has been attributed to the two competitive processes for its degradation.

- Taking this into mind, two types of properties have been revealed as the most influents: optical and microstructural and textural properties of the catalysts

- If light of enough energy is available to excite the catalysts, as higher the band gap, higher the efficiency of the photocatalytic reactions, due to higher redox power, following a potential trend.

- Concerning microstructure properties, the specific surface area, $\mathrm{S}_{\mathrm{BET}}$ and the total pore volume behave in the way of increasing the photocatalytic activity as increasing these parameters, according a potential trend for NOx and linear trend for tobacco degradation.

- Concerning the different crystal phases, the synergetic effect of the combination anatase/rutile was not clearly detected in these results; pure 
rutile samples were fewer actives for all the contaminants than that made of pure anatase and that combined anatase/rutile. The size of the crystals does not seem to have special relevance, not having detected in this research clear QSE. The degree of cristallinity (FWHM) seems to be more relevant, increasing the efficiency as the cristallinity decreases.

\section{ACKNOWLEDGMENTS}

The authors thank the Ministry of Economy and Competitivity the funding provided through the project BIA 2011-25653 "TELEPASSCLOR" granted within the Spanish National Plan of $\mathrm{R}+\mathrm{D}+\mathrm{i}$.

\section{REFERENCES}

1. Fujishima, A.; Honda, K. (1972) Electrochemical Photolysis of Water at a Semiconductor Electrode. Nature, 238, 37-38. http://dx.doi.org/10.1038/238037a0.

2. Wrighton, M.S.; Ellis, A.B.; Wolczanski, P.T.; Morse D.L.; Abrahamson, H.B.; Ginley, D.S. (1976) Strontium titanate photoelectrodes. Efficient photoassisted electrolysis of water at zero applied potential. J. Am. Chem. Soc. 98, 2774. http://dx.doi.org/10.1021/ja00426a017.

3. Stirini A.; Cassese L.; Schiavi L. (2005). Measurement of benzene, toluene, ethylbenzene and o-xylene gas phase photodegradation by titanium dioxide dispersed in cementitious materials using a mixed flow reactor. Applied Catalysis B: Environmental 61, 90-97. http://dx.doi.org/10.1016/j. apcatb.2005.04.009

4. Demeestere K.; Dewulf J.; Witte B.D.; Baeldens A.; Langenhove H.V. (2008) Heterogeneous photocatalytic removal of toluene from air on building materials enriched with $\mathrm{TiO}_{2}$. Building and Environment 43, 406-414. http:// dx.doi.org/10.1016/j.buildenv.2007.01.016.

5. Maury A.; Demeestere K.; De Belie N.; Mäntylä T.; Levänen E. (2010). Titanium dioxide coated cementitious materials for air purifying purposes: Preparation, characterization and toluene removal potential, Building and Environment 45, 832-838. http://dx.doi.org/10.1016/j. buildenv.2009.09.003

6. Cassar L. (2004) Photocatalysis of cementitious materials: Clean buildings and clean air. Materials Research Society 29, 328-331. http://dx.doi.org/10.1557/mrs2004.99.

7. Hüsken G.; Hunger M.; Brouwers H.J.H. (2009) Experimental study of photocatalytic concrete products for air purification. Building and Environment 44, 2463-2474. http://dx.doi. org/10.1016/j.buildenv.2009.04.010.

8. Bengtsson, N.; Castellote, M. (2010) Photocatalytic Activity for NO degradation by construction materials: Parametric study and multivariable correlations. Journal of Advanced Oxidation Technology, 13, 341-349.

9. De Melo J.V.S.; Trichês G. (2012) Evaluation of the influence of environmental conditions on the efficiency of photocatalytic coatings in the degradation of nitrogen oxides (NOx). Building and Environment, 49, 117-123. http://dx.doi.org/10.1016/j.buildenv.2011.09.016.

10. Peruchon, L.; Puzenat, E.; Herrmann, J.M.; Guillard, C. (2009) Photocatalytic efficiencies of self-cleaning glasses. Influence of physical factors Photochemistry and Photobiology A: Chemistry, 8, 1040-1046.

11. Ruot, B.; Plassais, A.; Olive, F.; Guillot, L.; Bonafous, L. (2009) $\mathrm{TiO}_{2}$-containing cement pastes and mortars: Measurements of the photocatalytic efficiency using a Rhodamine B-based colourimetric test, Solar Energy 83, 1794-1801. http://dx.doi. org/10.1016/j.solener.2009.05.017

12. Sapiña, M.; Jimenez-Relinque, E.; Castellote, M. (2013) Controlling the Levels of Airborne Pollen: Can Heterogeneous Photocatalysis Help?, Environ. Sci. Technol. 47, 11711-11716.
13. Folli, A.; Pochard, I.; Nonat, A.; Jakobsen, U.H.; Shepherd, A.M.; Macphee, D.E. (2010) Engineering Photocatalytic Cements Understanding $\mathrm{TiO}_{2}$ Surface Chemistry to Control and Modulate Photocatalytic Performances, J. Am. Ceram. Soc. 93, [10] 3360-3369 http://dx.doi.org/10.1111/j. 1551-2916.2010.03838.x.

14. Lucas, S.S.; Ferreira, V.M.; Barroso de Aguiar, J.L. (2013) Incorporation of titanium dioxide nanoparticles in mortars -Influence of microstructure in the hardened state properties and photocatalytic activity, Cem. Concr. Res. 43, 112 120. http://dx.doi.org/10.1016/j.cemconres.2012.09.007.

15. Diamanti, M.V.; Lollini, F.; Pedeferri,M.P.; Bertolini, L. (2013) Mutual interactions between carbonation and titanium dioxide photoactivity in concrete, Building and Environment 62, 174e181. http://dx.doi.org/10.1016/j.buildenv.2013.01.023.

16. Brus, L. (1984) Electron-electron and electron-hole interactions in small semiconductor crystallites: The size dependence of the lowest excited electronic state. J. Chem. Phys. 80, 4403-4409.

17. Brus, L. (1986) Electronic wave functions in semiconductor clusters: experiment and theory. Phys. Chem. 90, [12] 2555-2560. http://dx.doi.org/10.1021/j100403a003.

18. Rino, J.P.; Studart, N. (1999) Structural correlations in titanium dioxide. Phys. Rev. B 59, 6643-6649.

19. Anpo, M.; Shima, T.; Kodama, S.; Kubokawa, Y. (1987) Photocatalytic hydrogenation of propyne with water on small-particle titania: size quantization effects and reaction intermediates. J. Phys. Chem. 91, 4305-4310. http://dx.doi. org/10.1021/j100300a021.

20. Kormann, C.; Bahnemann, D.W.; Hoffmann, M.R. (1988) Preparation and characterization of quantum-size titanium dioxide. J. Phys. Chem. 92, 5196-5201. http://dx.doi. org/10.1021/j100329a027.

21. Kavan, L.; Stoto, T.; Gratzel, M.; Fitzmaurice, D.; Shklover, V. (1993) Quantum-size effects in nanocrystaline semiconducting $\mathrm{TiO}_{2}$ layers prepared by anodic oxidative hydrolysis of TiCl3. J. Phys. Chem. 97, (37) 9493-9498. http://dx.doi. org/10.1021/j100139a038.

22. Serpone, N.; Lawless, D.; Khairatdinov, R.; (1995) Size Effects on the Photophysical Properties of Colloidal Anatase $\mathrm{TiO}_{2}$ Particles: Size Quantization versus Direct Transitions in This Indirect Semiconductor?. J. Phys. Chem. 99, 1664616654. http://dx.doi.org/10.1021/j100045a026.

23. Tanaka, K.; Lapule, M.F.V.; Hisanaga, T.(1991)Effect of crystallinity of $\mathrm{TiO}_{2}$ on its photocatalytic action. Chem. Phys. Lett. 187, 73-76. http://dx.doi.org/10.1016/0009-2614(91)90486-S.

24. Maira, A.J.; Yeung, K.L.; Lee, C.Y.; Yue, P.L.; Chan, C.K.; (2000) Size Effects in Gas-Phase Photo-oxidation of Trichloroethylene Using Nanometer-Sized $\mathrm{TiO}_{2}$ Catalysts. J. Catal. 192, 185-196. http://dx.doi.org/10.1006/jcat.2000.2838.

25. Almquist, C.B.; Biswas, P. (2002) Role of Synthesis Method and Particle Size of Nanostructured $\mathrm{TiO}_{2}$ on Its Photoactivity. J. Catal. 212, 145-156. http://dx.doi.org/10.1006/ jcat.2002.3783.

26. Byrne, J.A.; Eggins, B.R.; Dunlop, P.S.M.; LinquetteMailley, S. (1998) The effect of hole acceptors on the photocurrent response of particulate $\mathrm{TiO}_{2}$ anodes. Analyst 123, 2007-2012. http://dx.doi.org/10.1039/a803885f.

27. Jang, H.D.; Kim, S.J.; Kim, S.K. (2001) Effect of Particle Size and Phase Composition of Titanium Dioxide Nanoparticles on the Photocatalytic Properties. J. Nanoparticle Res. 3, 141-147. http://dx.doi.org/10.1023/A:1017948330363.

28. Nam, H.J; Amemniya, T.; Murabayashi, M.; Itoh, K. (2004) Photocatalytic Activity of Sol-Gel TiO 2 Thin Films on Various Kinds of Glass Substrates: The Effects of $\mathrm{Na}+$ and Primary Particle Size. J. Phys. Chem. B 108, 8254-8259. http://dx.doi.org/10.1021/jp037170t.

29. Zhang, Z.; Wang, C.C.; Zakaria, R.; Ying, J.Y. (1998) role of particle size in nanocrystalline $\mathrm{TiO}_{2}$-based photocatalysts. $J$. Phys. Chem. B 102, 10871-10878. http://dx.doi.org/10.1021/ jp982948+.

30. Xu, N.; Shi, Z.; Fan, Y.; Dong, J.; Shi, J.; Hu, M.Z.C. (1999) Effects of Particle Size of $\mathrm{TiO}_{2}$ on Photocatalytic Degradation of Methylene Blue in Aqueous Suspensions. Ind. Eng. Chem. Res. 38, 373-379. http://dx.doi.org/10.1021/ ie980378u. 
31. Gerischer, H. (1995) Photocatalysis in aqueous solution with small $\mathrm{TiO}_{2}$ particles and the dependence of the quantum yield on particle size and light intensity. Electrochim. Acta, 40, 1277 1281. http://dx.doi.org/10.1016/0013-4686(95)00058-M.

32. Grela, M.A.; Colussi, A.J. (1996) Kinetics of Stochastic Charge Transfer and Recombination Events in Semiconductor Colloids. Relevance to Photocatalysis Efficiency. $J$. Phys. Chem. 100, 18214-18221. http://dx.doi.org/10.1021/ jp961936q.

33. Lin, H.; Huang, C.P.; Li, W.; Ni, C.; Ismat Shah, S.; Tseng, Y. (2006) Size dependency of nanocrystalline $\mathrm{TiO}_{2}$ on its optical property and photocatalytic reactivity exemplified by 2-chlorophenol, Applied Catalysis B: Environmental, 681 . http://dx.doi.org/10.1016/j.apcatb.2006.07.018.

34. Folli, A.; Pade, C.; Hansen, T.B.; De Marco, T.; Macphee, D.E. (2012) $\mathrm{TiO}_{2}$ photocatalysis in cementitious systems: Insights into self-cleaning and depollution chemistry, Cem. Concr. Res, 42, 539-548. http://dx.doi.org/10.1016/j. cemconres.2011.12.001.

35. Puddu, V.; Choi, H.; Dionysiou, D.D.; Li Puma, G. (2010) $\mathrm{TiO}_{2}$ photocatalyst for indoor air remediation: Influence of crystallinity, crystal phase, and UV radiation intensity on trichloroethylene degradation. Applied Catalysis B: Environmental, 94, 211-218. http://dx.doi.org/10.1016/j. apcatb.2009.08.003.

36. Bengtsson, N.; Castellote, M.; López-Muñoz, M.; Cerro, L. (2009) Preparation of Co-doped $\mathrm{TiO}_{2}$ for Photocatalytic Degradation of NOx in Air under Visible Light. Journal of Advanced Oxidation Technologies, 12, 55-64.

37. G.F.A. Kortum, (1969) Reflectance Spectroscopy: Principles, Methods, Applications, New York. http://dx.doi.org/ 10.1007/978-3-642-88071-1

38. Augugliario, V.; Kisch, H.; Loddo, V.; López-Muñoz, M.; Márquez-Álvarez,C.;Palmisano,G.;Palmisano,F.Parrino,F.;
Yurdakal. S. (2008) Photocatalytic oxidation of aromatic alcohols to aldehydes in aqueous suspension of home prepared titanium dioxide: 2 . Intrinsic and surface features of catalysts. Applied Catalysis A: General, 349, 189-197. http:// dx.doi.org/10.1016/j.apcata.2008.07.038.

39. ISO 22197-1: Fine ceramics (advanced ceramics, advanced technical ceramics)-Test method for air-purification performance of semiconducting photocatalytic materials-Part 1: Removal of nitric oxide, 2007.

40. UNI 11259: Determinazione dell'attività fotocatalitica de leganti idraulici-Metodo della rodamina 2008.

41. Luo, Y.; Tai, W.S.; Seo, H.O.; Kim, K.; Kim, M.J.; Dey, N.K.; Kim, Y.D.; Choi, K.H.; Lim, D. (2010) Adsorption and Photocatalytic Decompositon of Toluene on TiO2 Surfaces. Catalysis Letters, 138, 76-81. http://dx.doi.org/10.1007/ s10562-010-0369-1.

42. Monticone, S.; Tufeu, R.; Kanaev, A.V.; Scolan, E.; Sanchez, C. (2000) Quantum size effect in $\mathrm{TiO}_{2}$ nanoparticles: does it exist?, Applied Surface Science, 162-163, 565570. http://dx.doi.org/10.1016/S0169-4332(00)00251-8.

43. Perez-Estrada, L.A.; Aguera, A.; Hernando, M.D.; Malato, S.; Fernandez, A. (2008) AR Photo degradation of malachite green under natural sunlight irradiation: kinetic and toxicity of the transformation products. Chemosphere 70, 2068-2075 http://dx.doi.org/10.1016/j.chemosphere.2007.09.008.

44. Fu, H.B.; Zhang, S.C: Xu, T.G.; Zhu, Y.F; Chen, J.M (2008) Photocatalytic degradation of RhB by fluorinated Bi2WO6 and distributions of the intermediate products. Environ Sci Technol,42, 2085-2091. http://dx.doi.org/10.1021/es702495w.

45. Natarajan, T.S.; Natarajan, K.; Bajaj, H.C.; Tayade, R.J. (2013) Enhanced photocatalytic activity of bismuth-doped $\mathrm{TiO}_{2}$ nanotubes under direct sunlight irradiation for degradation of Rhodamine B dye, $J$ Nanopart Res, 15, 1669. http://dx.doi.org/10.1007/s11051-013-1669-3. 